DOI :10.31357/fapsmst.2006.00498

\title{
NUTRITIONAL AND SENSORY PROPERTIES OF BOTTLED LOTUS RHIZOME
}

\author{
By \\ Chandraprabha Manoji Ranawaka
}

M.Sc.

2006 


\title{
NUTRITIONAL AND SENSORY PROPERTIES OF BOTTLED LOTUS RHIZOME
}

\author{
By
}

Chandraprabha Manoji Ranawaka

Thesis submitted to the University of Sri Jayawardenapura for the award of Degree of Master of Science in Food Science and Technology in 2006. 


\section{Delaration}

The work described in this thesis was carried out by me under the supervision of Prof.

Shiromi Samarasinghe and Mr. M.A.J Wansapala and a report on this has not been submitted in whole or in part to any other institution for another DegreelDiploma.

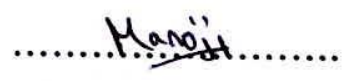

C.M. Ranawaka 
We certify that above statement made by the candidate is true and that this thesis is suitable for submission to the university for the purpose of evaluation.

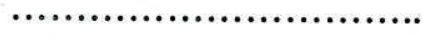

Signature

Prof. Shiromi Samarasinghe

Associate Professor

Department of Chemistry

University of Sri Jayawardenepura

Sri Lanka

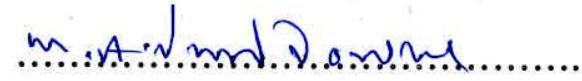

\section{Signature}

Mr. M.A.J Wansapala

Lecture

Department of food Science and Technolo

University of Sri Jayawardenepura

Sri Lanka. 
List of tables $\quad$ iv

List of figures $\quad \mathrm{v}$

Abbreviations $\quad$ v

Acknowledgement $\quad$ vi

Abstract vii

Chapter 1

Introduction

Chapter 2

Literature Review 3

2.1 General Description 3

2.1.1 Lotus 3

2.2 Minimally processed 5

2.3 Process flow chart in increasing shelf life in $\quad 7$

minimally processed lotus rhizome

Chapter 03

$\begin{array}{ll}\text { Experimental } & 12\end{array}$

3.1 Determination of the $\mathrm{pH}$ value of bottled lotus rhizome 12

3.2 Determination a Method for increasing shelf life of lotus 12

Rhizome

3.3 Methods of chemical Analysis 15

3.3.1 Determination of protein content (Kjeldahl Method) 15 
3.3.2 Determination of moisture content (Oven drying method) 16

3.3.2.1 Materials 16

3.3 3 Determination of crude fibre content 17

3.3.3.1 Materials:

3.3.2.2 Method

3.3.3 Determination of Total ash content 18

3.3.3.1 Materials 18

3.3.3.2 Method 18

3.3.4 Determination Acid insoluble ash of content 19

3.3.4.1 Materials 19

3.3.4.2 Method 19

3.4 Analysis of microorganism (Bacteria and Fungi)

3.4.1 Nutrient Agar media preparation

3.4.2 Potato dextrose agar media preparation 20

3.4.2.1 Method 20

3.4.2.2 Method 20

3.4.3 Streak plate method 21

3.4.3.1 Material 21

3.4.3.2 Method 21 
Chapter 4

4.0 Results and Discussion

after its shelf life by using Methyl red test 


\section{LIST OF TABLES}

(1) Combination of blanching and SMS treatments 14

(2) Combination of Ascorbic acid and citric acid used in place of lime juice

(3)Analysis of $\mathrm{PH}$ and microorganism

(4)Analysis of microorganism of Experiment No 12 in details

(5)Analysis of microorganism of Experiment No 15 in details

(6)Analysis of microorganism of Experiment No 20 in details

(7)Analysis of microorganism of Experiment No 22 in details

(8)Identification of micro organism in experiment No 12,15,22

after its shelf life by using Methyl red test

(9)Chemical analysis of lotus rhizome

(10) Testing the significance of the mean difference of

two samples of lotus rhizome curry( $\mathrm{T}$ and $\mathrm{P}$ value)

(11)Testing the significance of the mean difference of two samples of lotus rhizome curry(Mean and St. Deviation) 


\section{LIST OF FIGURES}

(1) 9 weeks old preserved lotus rhizome in Ex No: 15

(2)Bacteria analysis by using Nutrient agar $\quad 26$

9weeks old preserved lotus rhizome in Ex No: 15

(3) Fungus analysis by using Potato dextrose agar

9weeks old preserved lotus rhizome in Ex No: 15

(4)E Coli analysis by using Methyl red test in Ex No: 15

(5) Descriptive Analysis on lotus rhizome curry

1 Data analysis Appearance $\quad 30$

2 Data analysis Aroma $\quad 30$

$\begin{array}{ll}3 \text { Data analysis Taste } & 31\end{array}$

4 Data analysis Texture $\quad 31$

5 Data analysis overall acceptability $\quad 32$

\section{ABBREVIATIONS}

ENA - Nutrient agar

(2)PDA - Potato Dextroxe agar 


\section{Acknowledgement}

I wish to offer my sincere gratitude to supervisors Prof. Shiromi Samarasinghe \& Mr M.A.J Wansapala for their valuable advice, suggestions \& guidance given to me.

I offer my heartiest gratitude to Dr. K.K.D.S. Ranaweera and Prof. Arthur Bamunuarachchi for their valuable instructions and advice throughout the project.

I wish to express my sincere gratitude to all lectures in the Food Science \& Technology M.Sc. programme, for enlightening me with the knowledge and skills needed to carry out the research.

I am greatly indebted to all laboratory staff members of the Department of Food Science and Technology, University of Sri Jayewardenepura for their support and help given during tenure of my project. 


\section{Nutritional and sensory properties of bottled lotus rhizome}

\section{By}

\section{C.M Ranawaka}

\section{ABSTRACT}

Lotus rhizome is rich in fibre content and therefore it is a popular commodity among local communities. In addition to fibre, it contains high amounts of calcium and can be a good calcium sources for children and pregnant women to meet their daily calcium requirements. It is also reported that it contains zero fat which makes it good for individuals having heart and high blood pressure complications. Although lotus rhizome can be prepared into different delicious dishes, it is regularly not available to urban communities. Lotus plants are commonly available among the natural water reservoir, and major supplies came from north east of our country. A shortage in supply of lotus rhizomes can be observed during the monsoon rain period from December to February. During rainy season this commodity is very difficult to find in the market.

A study was carried out to increase the shelf-life of bottled lotus rhizome. A treatment system which included sorting, cleaning, peeling, cutting and steam blanching for 3 minutes and packaged in $3 \%$ salt solution, exhausting and pasteurization was found to be the best among the treatments and conditions tested in this study.

The manufacturing of bottled lotus rhizome has been successful. The keeping quality of the product was satisfactory. Lotus rhizome can be stored more than two mopths without fungal and bacterial contamination. Chemical analysis confirmed that the bottled lotus rhizome has a similar nutritional value compared with its fresh counterparts. The sensory evaluation showed that the bottled lotus rhizome has a good sensory acceptance. 


\section{Chapter 01}

\section{Nutritional and Sensory properties of bottled lotus Rhizome}

\section{Introduction}

Fruit and vegetables are important sources of essential minerals and vitamins in the human diet. These commodities contain significant amounts of calcium, iron and some other minerals required for health. Sodium, potassium, iron, calcium, phosphorus and many trace elements play an essential role in our body functions. Vitamins too are essential for the control of chemical reactions in the body. Vegetables are also important sources of vitamin C and other essentials. Fibre or "roughage" is found in large amounts in these fresh produce. Though indigestible, it plays an important part in the function of digestion, and a diet containing high fibre content is shown by medical studies to reduce susceptibility to disease. Lotus rhizomes contain relatively high fibre content. Therefore it was consumed to improve the digestion process and recommended for our commonly diagnosed diseases. (Ex: Diabetic mellitus) In addition to fibre, It has high calcium which is highly recommended to children and pregnant women to their daily calcium requirements. Lotus rhizome is a rare food containing zero fat and therefore is good for heart and high blood pressure patients. Therefore taking lotus rhizomes as a vegetable for a diet is most advised by Auyrvedic and Weston medical practitioners. Lotus rhizome can be found in rural areas in lakes, ponds and reservoirs but it is difficult to harvest it entire year. Therefore, it is necessary to find out a low cost method to preserve lotus rhizomes without affecting its nutritional value and sensory qualities. 


\section{The objectives of the project}

Therefore, the objectives of the present study were the following;

(1) Increase the shelf life of lotus rhizomes by minimal processing and using a brine solution and package in a glass bottle.

(2) Comparatively analyze the nutrients of fresh and bottled lotus rhizome.

(3) Analyze sensory properties of bottled lotus rhizome. 


\section{Chapter 02}

\section{Literature Review}

\subsection{General Description}

\subsubsection{Lotus}

\section{Botanical Name Nelumbo nucifera gaertn}

Kingdom $=$ Plantae

Division $=$ Angiospera

Class $=$ Dicotyledonea

Family $=$ Nymphaeceae

Lotus (Nelumbo nucifera Gaertn.; Syn. Nelumbium speciosum Willd.), also called

Sacred Lotus and/or Indian Lotus originated in Asia, Persia, India and has spread to China and North Eastern areas of Australia. Lotus is a perennial, aquatic crop that is grown and consumed throughout Asia. Leaves, flowers, seeds and rhizomes are all edible the largest market, however, exists for rhizomes,

\section{World lotus production areas}

Lotus is cultivated in many countries in the world, especially in India, China, Japan,

Korea, South East Asia, Russia and some countries in Africa. Lotus grown in Europe and America is mainly used for ornamental purposes but rarely for food.

\section{Medicinal and nutritional values}

One of the wonderful components of fruits and vegetables is their indigestible fibre. As fibre passes through the digestive system, it sops up water like a sponge and expands. This can calm the irritable bowel and, by triggering regular bowel movements, can relieve or prevent constipation (Lembo, et al 2003). The bulking and softening action of insoluble fiber also decrease pressure inside the intestinal tract and so may help prevent diverticulosis (the 
development of tiny, easily irritated pouches inside the colon) and diverticulitis (Aldoori et al, 1998). Nutritional values of edible Lotus rhizomes are shown in Table1. (www.iamshaman.com/lotus/whitelotus.htm)

They are high in calcium, fibre and vitamine C(Lembo, et al 2003)

Its consumption is supposed to benefit liver function and is said to strengthen the heart, spleen and stomach. Uncooked lotus root juice clears "heat" and stops all internal bleeding; cooked lotus root can "promote blood," treat women for anemia from heavy menstruation and at the same time clear and improve energy. (www.foodsnherbs.com)

Table 1. Nutrient value of $100 \mathrm{~g}$ edible rhizome

$\begin{array}{lc}\text { Water } & 81.2 \\ \text { Energy,Kcal } & 66.0 \\ \text { Energy,Kj } & 276.0 \\ \text { Protein,(g) } & 2.1 \\ \text { Fat.g } & 0.00 \\ \text { Sugar,g } & 15.1 \\ \text { Dietary fibre,g } & 0.6 \\ \text { Calcium,mg } & 18.0 \\ \text { Phosphorus,mg } & 60.0 \\ \text { Iron,mg } & 0.6 \\ \text { Sodium,mg } & 28.0 \\ \text { Vitamin B1,mg } & 0.09 \\ \text { Vitamin B2,mg } & 0.02 \\ \text { Vitamin C,mg } & 55.0 \\ \text { Niacin,mg } & 0.2\end{array}$

